\title{
New-type highly stable 2D/3D perovskite materials: the effect of introducing ammonium cation on performance of perovskite solar cells
}

\author{
Haiying Zheng ${ }^{1,2}$, Songyuan Dai ${ }^{1,34^{*}}$, Kaixuan Zhou ${ }^{4}$, Guozhen Liu ${ }^{1,2}$, Bing Zhang ${ }^{4}$, Ahmed Alsaedi ${ }^{3}$, \\ Tasawar Hayat ${ }^{3,5}$ and $\mathrm{Xu} \mathrm{Pan}^{1 *}$
}

\begin{abstract}
Perovskite solar cells (PSCs) have drawn wide attention due to the rapidly rising efficiency which presently attains over $23 \%$. However, problems of instability continue to plague the high-efficiency devices impairing their practical applications. Here, by firstly introducing smaller-size $\mathrm{NH}_{4}{ }^{+}$ into $\left(\mathrm{FAPbI}_{3}\right)_{0.85}\left(\mathrm{MAPbBr}_{3}\right)_{0.15}$ (FA/MA) to form a novel 2D3D mixed structure, we designed and prepared new-type hybrid perovskite materials of $\left[\left(\mathrm{NH}_{4}\right)_{2.4}(\mathrm{FA})_{n-1} \mathrm{~Pb}_{n} \mathrm{I}_{3 n+1.4}\right]_{0.85}$ $\left(\mathrm{MAPbBr}_{3}\right)_{0.15}(n=3,5,7,9$ and 11) (A/FA/MA) and used them as absorber in solar cells. Especially, unlike the reported 2D/ MD perovskite perovskites based on larger-size ammonium salts; A/FA/MA perovskites are the first to display red-shift light absorption and decreased band gaps in comparison to normal perovskites. Consequently, when $n=9$, the A/FA/MA device shows outstanding performance with a solar to electric power conversion efficiency (PCE) of $18.25 \%$ and negligible hysteresis. When the encapsulated A/FA/MA perovskite device was soaked in full sunlight for $1,000 \mathrm{~h}$, the PCE remains almost unchanged. Moreover, the unsealed A/FA/MA PSCs maintain $90 \%$ of their initial PCE when aged at high humidity conditions over the same 1000-h time period. Our findings provide a guide for the future development of such novel perovskites and it is helpful to select more suitable ammonium salt to obtain highly efficient and stable 2D-3D PSCs.
\end{abstract}

Keywords: perovskite solar cells, new-type 2D/3D mixed perovskite, high performance, light stability, moisture resistance

\section{INTRODUCTION}

Hybrid 3-dimensional (3D) inorganic, organic metal halide perovskite solar cells (PSCs) have been increasingly studied since 2009 as solar light havesters due to their excellent photoelectric properties, high absorption coefficient, diversity, simple and low-cost preparation $[1,2]$. Today, the PSCs draw world-wide research attention, as a new and very promising photovoltaic technology. While the power conversion efficiency (PCE) of PSCs has been continuously increasing, reaching over 23\% [3-6], most of the high-efficiency formulations are still plagued by instability in particular when exposed to heat, light as well as oxygen and moisture [7-11].

Snaith et al. [12] have reported that the degradation of perovskite devices under light illumination lead to the recombination loss of photo-generated charges occurring in the $\mathrm{TiO}_{2}$ layers. Additionally, Lin et al. [13] have found that the decomposition of $\mathrm{MAPbI}_{3}$ can easily happen in a high moisture environment, because the interaction between highly hygroscopic methylammonium cations and water molecules can result in the dissociation of bonds among the crystal units.

There are many reports about improving the stability of perovskite [14-19]. One approach introduced in 2014 is to resort to $2 \mathrm{D}$ perovskite systems because they exhibit high moisture resistance [20-27]. Karunadasa et al. [22] studied $2 \mathrm{D}$ perovskite $\left[\mathrm{C}_{6} \mathrm{H}_{5}\left(\mathrm{CH}_{2}\right)_{2} \mathrm{NH}_{3}\right]_{2}(\mathrm{MA})_{2} \mathrm{~Pb}_{3} \mathrm{I}_{10}$ solar cells with a PCE of $4.73 \%$. More recently, Tsai et al.

\footnotetext{
${ }^{1}$ Key Laboratory of Photovoltaic and Energy Conservation Materials, Institute of Applied Technology, Hefei Institutes of Physical Science, Chinese Academy of Sciences, Hefei 230031, China

${ }^{2}$ University of Science and Technology of China, Hefei 230026, China

${ }^{3}$ NAAM Research Group, Department of Mathematics, Faculty of Science, King Abdulaziz University, Jeddah 21589, Saudi Arabia

${ }^{4}$ State Key Laboratory of Alternate Electrical Power System with Renewable Energy Sources, North China Electric Power University, Beijing 102206, China

${ }^{5}$ Department of Mathematics, Quaid-I-Azam University, Islamabad 44000, Pakistan

* Corresponding authors (emails: sydai@ncepu.edu.cn (Dai S); xpan@rntek.cas.cn (Pan X))
} 
[24] prepared 2D Ruddlesden-Popper perovskites $\left(\mathrm{CH}_{3}\right.$ $\left.\left(\mathrm{CH}_{2}\right)_{3} \mathrm{NH}_{3}\right)_{2}(\mathrm{MA})_{2} \mathrm{~Pb}_{3} \mathrm{I}_{10}(n=3)$ and $\left(\mathrm{CH}_{3}\left(\mathrm{CH}_{2}\right)_{3} \mathrm{NH}_{3}\right)_{2}-$ $(\mathrm{MA})_{3} \mathrm{~Pb}_{4} \mathrm{I}_{13} \quad(n=4)$ which show a PCE of $12.52 \%$ and longer-term stability against light and humidity. While these $2 \mathrm{D}$ perovskites contribute to stronger resistance of the devices against humidity, the PCE of $2 \mathrm{D}$ devices is still low.

To discover the reason for the low PCE, we carried out a set of simulation calculations (detailed simulation process as shown in Supporting Information (SI)). We found that the original corner-sharing $\left[\mathrm{PbI}_{6}\right]^{4+}$ octahedrons constructed 3D lattice was disconnected as described in Fig. S1 and lead to a poor photovoltaic performance when a slightly bigger A site group was put into the $\mathrm{FAPbI}_{3}$ lattice. Therefore, we proposed to mix FA with smaller groups, such as $\mathrm{NH}_{4}{ }^{+}$to ensure room for the motion of the bigger group to maintain the $3 \mathrm{D}$ lattice with the proper light absorption.

Here, we explored the influences of the A site group mixing on the spatial structure using different ratios of $\mathrm{NH}_{4}{ }^{+}$and $\mathrm{FA}^{+}$groups $(1: 7,2: 6,3: 5)$ (Fig. S1). We found that inserting $\mathrm{NH}_{4}{ }^{+}$did not perturb the $3 \mathrm{D}$ lattice, leading a new-type $2 \mathrm{D} / 3 \mathrm{D}$ mixed structure. Thus, we first introduced the smaller $\mathrm{NH}_{4}^{+}$into the $\left(\mathrm{FAPbI}_{3}\right)_{0.85^{-}}$ $\left(\mathrm{MAPbBr}_{3}\right)_{0.15}(\mathrm{FA} / \mathrm{MA})$ which is often-used as perovskite precursor with high PCE. We prepared the new-type perovskites based on the formula of $\left[\left(\mathrm{NH}_{4}\right)_{2.4}(\mathrm{FA})_{n-1}-\right.$ $\left.\mathrm{Pb}_{n} \mathrm{I}_{3 n+1.4}\right]_{0.85}\left(\mathrm{MAPbBr}_{3}\right)_{0.15}(n=3,5,7,9$ and 11) (A/FA/ $\mathrm{MA}$ ) and used them as light-absorbing layer to fabricate solar cells. The result illustrates that A/FA/MA perovskites indeed have $2 \mathrm{D} / 3 \mathrm{D}$ mixed structures which is greatly different from the reported 2D/MD perovskite structure based on larger-size ammonium salts. Compared to normal perovskite materials, the light absorption and photoluminescence of A/FA/MA perovskite films are red-shifted, showing narrower band gaps $\left(E_{\mathrm{g}}\right)$. Moreover, the solar cells based on the A/FA/MA $(n=9)$ perovskite materials have a PCE of $18.25 \%$ and negligible hysteresis. When exposed to AM $1.5 \mathrm{G}$ standard illumination over $1,000 \mathrm{~h}$, the PCE of the encapsulated A/FA/MA device remains stable. More importantly, under humidity exceeding $90 \%$ over $1,000 \mathrm{~h}$, the unsealed devices still show high performance and the PCE has no obvious decrease. As such the A/FA/MA perovskite materials have great prospects for the development of PSCs.

\section{EXPERIMEMTAL SECTION}

\section{Methodology of structural evolution}

All the 300 ps dynamics simulations were performed by the Car-Parrinello molecular dynamics module as implemented in the Quantum Espresso software suite $[28,29]$. The wave functions and the electronic density were expanded on a plane-wave basis set with a cutoff of $30 \mathrm{Ry}$ and $120 \mathrm{Ry}$, respectively. The Perdew-BurkeEzernhof implementation of the generalized gradient approximation was used for the description of the exchange-correlation functional, along with ultrasoft, scalar relativistic pseudopotentials for all atoms [30,31]. The target temperature was set to $300 \mathrm{~K}$ by a Nose thermostat [32]. All the atoms could move freely during the simulations. All the simulations were carried out with an integration time step of 5 a.u., a fictitious electronic mass of 400 a.u. and the real ionic masses. The structural models used for CPMD simulations are composed of a $2 \times 2 \times 2$ orthorhombic supercell $(93,90,87$ atoms for the 1:7, 2:6, 3:5 systems, respectively) with lattice parameters of $a$ $=10.303 \AA, b=9.482 \AA, c=17.288 \AA$ assigned from X-ray diffraction data. The cubic supercell is double size and contains the periodicity of the tetragonal unit cell (Pnma space group).

\section{Synthesis of formamidine iodide (FAI)}

FAI was synthesized by reacting $23.3 \mathrm{~g}$ of hydroiodic acid $(0.1 \mathrm{~mol}, 55 \mathrm{wt} . \%$ in water) with $10.3 \mathrm{~g}$ of formamidine acetate $(0.1 \mathrm{~mol})$. Hydroiodic acid was gradually added into formamidine acetate, and then the solution was allowed to stir in the ice bath for $2 \mathrm{~h}$. The white precipitate was collected by rotary evaporator at $60^{\circ} \mathrm{C}$ under reduced pressure. The production was recrystallized using methyl or ethanol and washed continuously with anhydrous diethyl ether until white powder was acquired.

\section{Fabrication of perovskite solar cells}

FTO-coated glass $(1.5 \mathrm{~cm} \times 2.0 \mathrm{~cm})$ was patterned by etching away a $2 \mathrm{~mm}$ strip with zinc powder and $4 \mathrm{~mol} \mathrm{~L}^{-1} \mathrm{HCl}$. Substrates were cleaned by sonication in detergent, and rinsed three times with ultrapure water and ethanol, respectively. Then it was dried on hotplate. A $\mathrm{TiO}_{2}$ compact layer was deposited on the cleaned FTOcoated glass by spray pyrolysis using air as the carrying gas at $460^{\circ} \mathrm{C}$ from a precursor solution of bis(acetylacetonate) $(0.4 \mathrm{~mL})$ and titanium diisopropoxide $(0.6 \mathrm{~mL})$ in anhydrous isopropanol $(7 \mathrm{~mL})$. A mesoporous $\mathrm{TiO}_{2}$ was coated on $\mathrm{TiO}_{2}$ compact layer by spincoating with a speed of $4,000 \mathrm{rpm}$ for $20 \mathrm{~s}$ with a ramp of $2,000 \mathrm{rpm} \mathrm{s}^{-1}$, from a particle paste $(30 \mathrm{~nm})$ which was diluted with ethanol with a weight ratio of 1:5.5. After the spin coating, mesoporous $\mathrm{TiO}_{2}$ substrates were then gradually annealed by heating from room temperature to 
$510^{\circ} \mathrm{C}$ for $3 \mathrm{~h}$ on hotplate. The light-absorber layers were deposited by spin-coating $1.3 \mathrm{~mol} \mathrm{~L}^{-1} \mathrm{~Pb}^{2+}$ perovskite precursor solutions in an air flowing glovebox first $1,000 \mathrm{rpm}$ for $10 \mathrm{~s}$, second $4,000 \mathrm{rpm}$ for $30 \mathrm{~s} .120 \mu \mathrm{L}$ of chlorobenzene was dropped on the spinning substrate during the spin-coating step $20 \mathrm{~s}$ before the end of the procedure. The substrate was then heated at $100^{\circ} \mathrm{C}$ for 60 min on a hotplate. The $\mathrm{Pb}^{2+}$ precursor solutions of $\left(\mathrm{FAPbI}_{3}\right)_{0.85}\left(\mathrm{MAPbBr}_{3}\right)_{0.15}, \quad\left[\left(\mathrm{NH}_{4}\right)_{2.4}(\mathrm{FA})_{n-1} \mathrm{~Pb}_{n} \mathrm{I}_{3 n+1.4}\right]_{0.85^{-}}$ $\left(\mathrm{MAPbBr}_{3}\right)_{0.15}(n=1,3,5,7,9$ and 11) were prepared by dissolving the corresponding amount of perovskite powders in anhydrous dimethylformamide (DMF) and dimethyl sulfoxide (DMSO) mixed solvent (DMF: $\mathrm{DMSO}=4: 1$ by volume) with stirring at $70^{\circ} \mathrm{C}$ for $30 \mathrm{~min}$ prior to film deposition. After cooling down to room temperature, the spiro-OMeTAD hole-transporting material (HTM) solution, comprised of spiro-OMeTAD $(73 \mathrm{mg}$ ), lithium bis-(trifluoromethanesulfonyl)imide, 4-tert-butylpyridine and cobalt(III) salt in chlorobenzene solvent, was then deposited on the perovskite layer by spin-coating at 3,000 rpm for $30 \mathrm{~s}$. Films were dried under vacuum before completing the device fabrication process by thermal evaporating $60 \mathrm{~nm}$ of gold on top of the HTM layer.

\section{RESULTS AND DISCUSSION}

We first performed a theoretical simulation of the structural evolution when $\mathrm{NH}_{4}{ }^{+}$insert into the $\mathrm{FAPbI}$ lattice. According to the crystal structure data [33-35], the skeleton of the inorganic part of $\mathrm{NH}_{4} \mathrm{PbI}_{3}$ is constructed by edge-sharing $\left[\mathrm{PbI}_{6}\right]^{4+}$ octahedrons that form a layered structure resembling that of $\mathrm{PbI}_{2}$. Considering the 3D perovskite structure [4], the edge-sharing model was adopted for the construction of the $\mathrm{NH}_{4}{ }^{+}$and $\mathrm{FA}^{+}$mixed systems. Starting structures with different ratios of $\mathrm{NH}_{4}^{+}$ and $\mathrm{FA}^{+}$groups $(1: 7,2: 6,3: 5)$ were designed and then put into $300 \mathrm{ps}$ dynamics simulations to explore the influences of the A site substitution. After certain time spans of fluctuations, as seen in the root-mean-square deviation curves, all the systems reached equilibrium (Fig. S2).

Taking the 2:6 mixing ratio of $\mathrm{NH}_{4}^{+}$and $\mathrm{FA}^{+}$as an example, the starting and equilibrated structures are depicted in Fig. 1a and b, respectively. During the dynamic processes, the $2 \mathrm{D}$ structure of the starting model changes to a structure between 2D and 3D. Examining the bond breaking and formation of the $\mathrm{Pb}$ and I atoms, we found that the part of edge-sharing $\mathrm{Pb}-\mathrm{I}$ bonds break. Then $\mathrm{Pb}$ and I atoms from different layers form new bonds during the dynamics processes, as described in Fig. 1c. These new bonds between different layers eventually result in a local 3D structure.

Together with the original 2D edge-sharing motif, the whole system appears as a 2D-3D mixed structure, which could be proper to explain the layered structure in SEM observations (Fig. 2). This bond formation is detected in all the $\mathrm{NH}_{4}^{+}$and $\mathrm{FA}^{+}$mixed designs.

Phase structures of FA/MA and A/FA/MA ( $n=3,5,7,9$ and 11) perovskites were then studied by using X-ray diffraction (XRD) measurements, and the results are also shown in Fig. $1 \mathrm{~d}$ and c. The peaks around $14^{\circ}$ and $28^{\circ}$ are identified as the scattering from (110) and (220) crystal planes, indicating a preferential orientation of crystallites and coinciding with the large crystal size seen in SEM images. According to the literature [36], there is no peak at $12.65^{\circ}$, implying that there are no $\mathrm{PbI}_{2}$. The absence of the above-mentioned peak in the present perovskite film suggests complete consumption of $\mathrm{PbI}_{2}$ in $\mathrm{A} / \mathrm{FA} / \mathrm{MA}$ $(n=3,5,7,9$ and 11) perovskites. These results are consistent with those of normal pure perovskite, indicating that the crystal growth in the perovskite film is not structurally affected by the addition of $\mathrm{NH}_{4} \mathrm{I}$. Whereas, if $\mathrm{NH}_{4} \mathrm{I}$ was added in the precursor solution, strong diffraction peaks at around $9.5^{\circ}$ and a series of corresponding weak peaks for the $2 \mathrm{D}$ perovskite phase (002), (004), (006) etc. crystal planes appear in the final mixed perovskite films. With $n$ increased, the intensities of A/FA/MA perovskites ( $n=3,5,7,9$ and 11) peaks at (002) crystal planes become weak, implying more normal perovskite structure formed while the $2 \mathrm{D}$ structure decreased. It indicates that there exist normal perovskite structure and 2D structure in A/FA/MA $(n=3,5,7,9$ and 11) perovskite films and the results are in accordance with above theoretical simulation. However, there are great difference between this $2 \mathrm{D}$ perovskite structure composed of smaller-size $\mathrm{NH}_{4}{ }^{+}$and other reported 2D/ $\mathrm{MD}$ perovskite structure based on larger-size ammonium salts [20-25], and thus, we defined this 2D-3D mixed perovskites as new-type perovskite materials. Additionally, from Fig. 1e and Fig. S3a, b, we found that with increased addition of $\mathrm{NH}_{4} \mathrm{I}$ ( $n$ decrease), the peaks position slightly moves toward larger angles (except $n=3$ ) representing a change in crystal lattice constants, chiefly an expansion of the $c$-axis of the perovskite unit cell that is responsible for the differences in $E_{g}$.

To further reveal the crystalline orientation of new-type 2D/3D mixed perovskites, the grazing-incidence wideangle X-ray scattering (GIWAXS) of FA/MA $(n=\infty)$ and A/FA/MA ( $n=3$ and 9 ) perovskites were carried out. In the 2D GIWAXS data (Fig. 1f, g), the three perovskites all show five distinct Debye-Scherrer rings along certain 

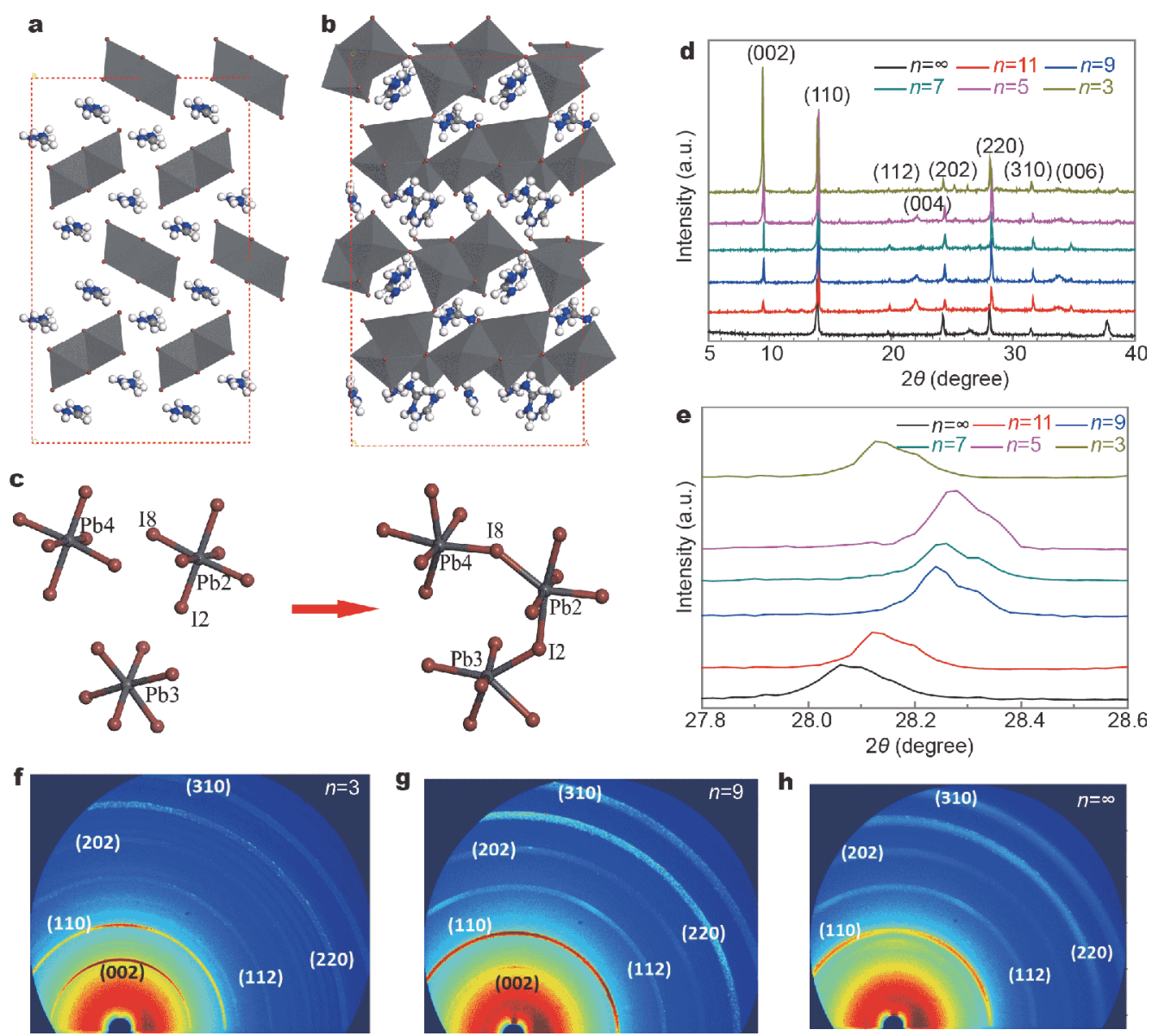

Figure 1 (a) The starting and (b) the equilibrated structure of the $\mathrm{NH}_{4}^{+}$and $\mathrm{FA}^{+}$mixed (2:6) $\mathrm{APbI}_{3}$ system, respectively. (c) An example of the bond formation of $\mathrm{Pb}$ and $\mathrm{I}$ from different $\left[\mathrm{PbI}_{6}\right]^{4+}$ layers during the dynamics processes. (d, e) XRD patterns and (f-h) 2D GIWAXS data of $\left(\mathrm{FAPbI}_{3}\right)_{0.85}\left(\mathrm{MAPbBr}_{3}\right)_{0.15}(n=\infty)$ and $\left[\left(\mathrm{NH}_{4}\right)_{2.4}(\mathrm{FA})_{n-1} \mathrm{~Pb}_{n} \mathrm{I}_{3 n+1.4}\right]_{0.85}\left(\mathrm{MAPbBr}_{3}\right)_{0.15}(n=3,5,7,9$ and 11) thin films.

extended arc segments which indicate strong intensities of the (110), (112), (202), (220), and (310) crystal planes. It reveals that the three perovskites all have preferential 3D perovskite orientation of crystallites. Whereas, for 2D GIWAXS of A/FA/MA ( $n=3$ and 9), the new DebyeScherrer rings in the inner yellow area can be ascribed to (002) crystal planes with a 2D in-plane random orientation. The results are in accord with the XRD patterns and further prove the formation of new 2D-3D mixed perovskite materials.

The morphologies of FA/MA and A/FA/MA $(n=3,5,7$, 9 and 11) perovskites were examined by a scanning electron microscope (SEM). Fig. 2 shows the top surface and cross-sectional SEM images of A/FA/MA $(n=3,9)$ and FA/MA $(n=\infty)$ on $\mathrm{TiO}_{2}$ films. A complete set of SEM images $(n=3,5,7,9,11, \infty)$ are presented in Figs $S 4$ and S5. Generally, the orientation of 2D materials on substrates strongly favors growth of layered structures where the layers orient parallel to the substrate. However, if the layers become thicker $(n>1)$, a competition arises between the $\mathrm{NH}_{4}{ }^{+}$ions (confining the growth layer), and the $\mathrm{FA}^{+}$ and $\mathrm{MA}^{+}$ions (expanding the perovskite and forming larger grains). A trend has been observed in A/FA/MA perovskites. The crystals are composed of layer growth structures and large grain to form $2 \mathrm{D} / 3 \mathrm{D}$ mixed structures, and then these perovskites are self-assembled to form well defined films on the substrates with excellent surface coverage and a fine texture. With increasing $n$, the small grains are subsequently interconnected to each other, leading to large grain size and layer structures gradually disappear.

Optical properties and $E_{\mathrm{g}}$ are closely related to the photovoltaic performance of the solar cells. To exhibit the effect of the A/FA/MA ( $n=3,5,7,9$ and 11) perovskites on the optical properties, we compared the UV-vis absorption and normalized photoluminescence (PL) spectra 

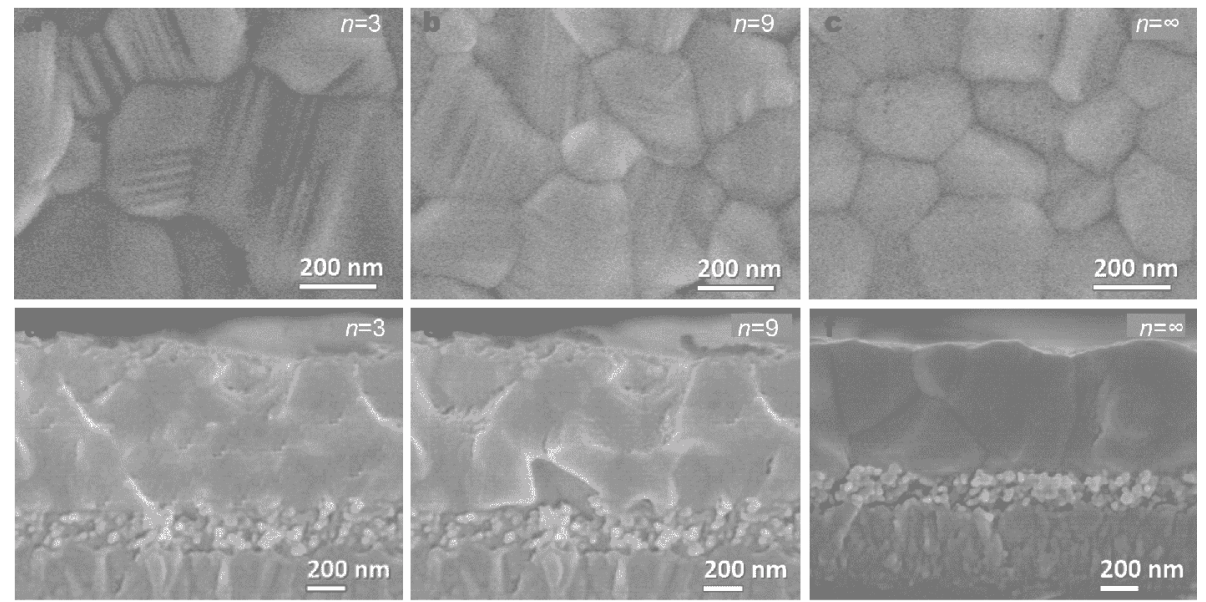

Figure $2(\mathrm{a}-\mathrm{c})$ Top view and $(\mathrm{d}-\mathrm{f})$ cross-sectional SEM images of $\left[\left(\mathrm{NH}_{4}\right)_{2.4}(\mathrm{FA})_{n-1} \mathrm{~Pb}_{n} \mathrm{I}_{3 n+1.4}\right]_{0.85}\left(\mathrm{MAPbBr}_{3}\right)_{0.15}(n=3,9)$ and $\left(\mathrm{FAPbI}_{3}\right)_{0.85}\left(\mathrm{MAPbBr}_{3}\right)_{0.15}$ $(n=\infty)$ perovskites on top of mesoporous $\mathrm{TiO}_{2}$ layer.

of perovskite thin films of the FA/MA $(n=\infty)$ and A/FA/MA ( $n=3,5,7,9$ and 11) perovskites which are given in Fig. 3. Interestingly, compared to thin film of FA/MA $(n=\infty)$, the UV-vis absorption peaks position of A/FA/MA $(n=3,5,7,9$ and 11) films all show red-shift (Fig. 3a). The smaller $n$ values, the more the light absorption of these A/FA/MA perovskite films shifts to

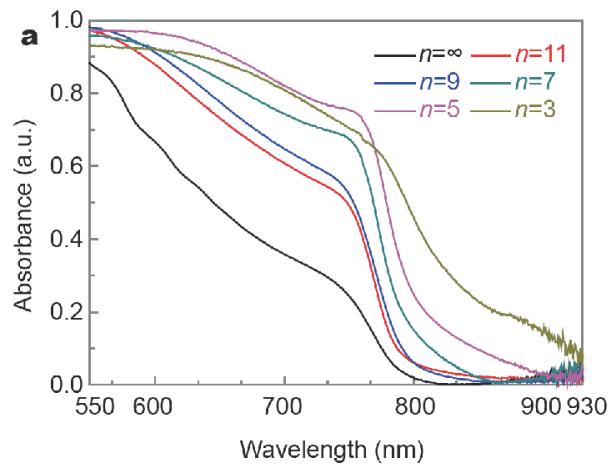

C

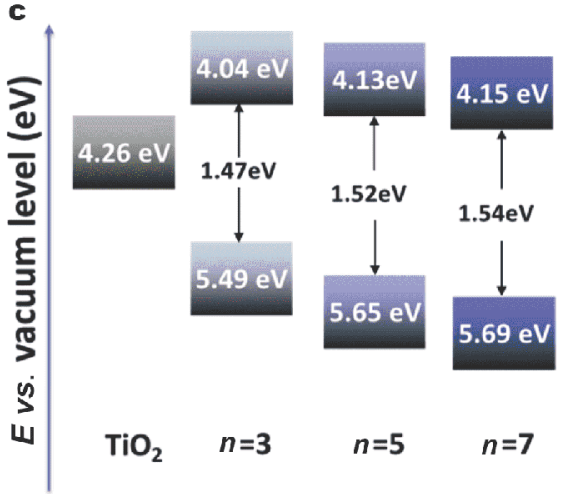

longer wavelength region. Normalized PL spectra of the perovskite film of FA/MA $(n=\infty)$ and A/FA/MA $(n=3,5$, 7, 9 and 11) perovskites (Fig. 3b) also show a red-shift and the PL peak of A/FA/MA ( $n=3)$ perovskite has the greatest red shift.

To gain better insight into $E_{\mathrm{g}}$ and the charge transport dynamics in the A/FA/MA perovskite devices, the energy
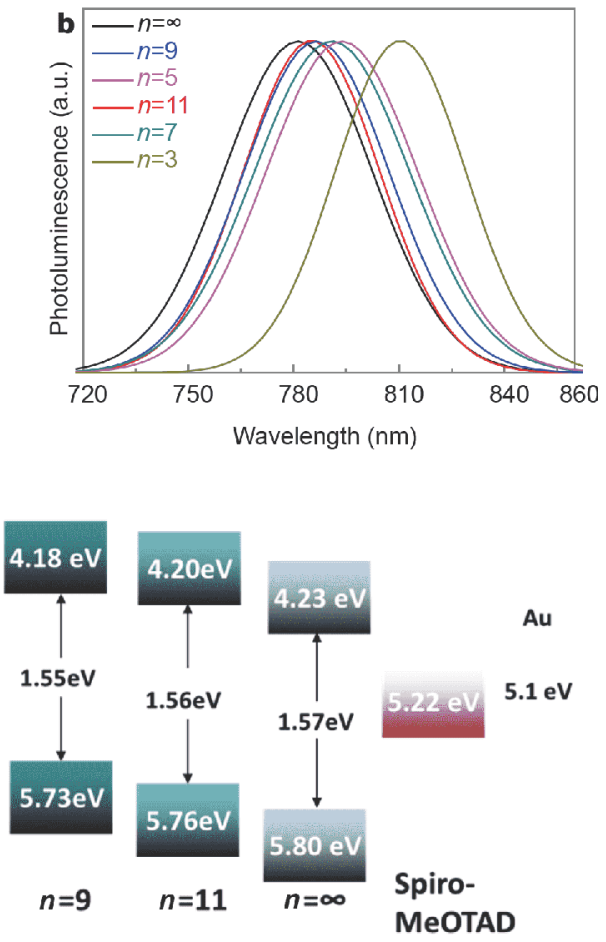

Figure 3 (a) UV-vis spectra, (b) normalized PL spectra and (c) energy diagram of thin films of the $\left(\mathrm{FAPbI}_{3}\right)_{0.85}\left(\mathrm{MAPbBr}_{3}\right)_{0.15}(n=\infty)$ and $\left[\left(\mathrm{NH}_{4}\right)_{2.4}(\mathrm{FA})_{n-1} \mathrm{~Pb}_{n} \mathrm{I}_{3 n+1.4}\right]_{0.85}\left(\mathrm{MAPbBr}_{3}\right)_{0.15}(n=3,5,7,9$ and 11) perovskite. 
level diagram of the components in the device is depicted in Fig. 3c. The highest occupied molecular orbital (HOMO) energy levels of FA/MA $(n=\infty)$ and A/FA/MA $(n=3,5,7,9$ and 11) perovskites are determined from ultraviolet photoelectron spectroscopy (UPS). The lowest unoccupied molecular orbital (LUMO) energy levels were determined by subtracting the VBM from the corresponding $E_{\mathrm{g}}$. As shown in Fig. $3 \mathrm{c}$, the $E_{\mathrm{g}}$ for the A/FA/MA perovskites with $n=3,5,7,9$ and 11 are smaller compared to the pure FA/MA ( $n=\infty$ phase), causing the observed shift in the UV-vis absorption bands and in the PL peaks of the perovskite films. Thus, $\mathrm{NH}_{4}^{+}$plays a crucial role in the red shift of UV-vis absorption, PL peaks and $E_{\mathrm{g}}$. It is contributed to that $\mathrm{NH}_{4} \mathrm{PbI}_{3}$ could be sensitive towards longer wavelengths. Previously reported $\left(\mathrm{NH}_{4}\right)_{x^{-}}$ (MA $)_{1-x} \mathrm{PbI}_{3}$ mixed perovskite could be used to adjust the absorption onset [37]. The lower $E_{\mathrm{g}}$ are potentially obtained from smaller molecular cations and the replacement of $\mathrm{FA}^{+}$by $\mathrm{NH}_{4}{ }^{+}$in the perovskite lattice reduces the band gap by $0.3 \mathrm{eV}$ [38]. As a consequence, the A/FA/MA perovskites could significantly improve the light harvesting capability of solar cell making an excellent choice as light-absorbing layer because of the lower $E_{\mathrm{g}}$.

As stated in the above section, the attractive optical properties of the A/FA/MA $(n=3,5,7,9$ and 11) perovskite films show great applied potential in solar cells. Hence, we proceeded to study the impact of A/FA/MA with different $n$ values on photovoltaic performance. The devices based on these A/FA/MA $(n=3,5,7,9$ and 11) films were fabricated and the corresponding photo-current and voltage curves were measured. The overall A/FA/MA ( $n=3,5,7,9$ and 11) devices showed much better PCE performance than previous reports for $2 \mathrm{D}$ and MD PSCs, with $\left[\left(\mathrm{NH}_{4}\right)_{2.4}(\mathrm{FA})_{8} \mathrm{~Pb}_{9} \mathrm{I}_{28.4}\right]_{0.85}\left(\mathrm{MAPbBr}_{3}\right)_{0.15}$ formulations $(n=9)$ devices exhibiting the highest PCE. Upon augmenting $n$ from 3 to 9 , the $J_{\text {sc }}$ constantly increase from 13.49 to $22.12 \mathrm{~mA} \mathrm{~cm}^{-2}, V_{\mathrm{oc}}$ increases from 0.95 to $1.05 \mathrm{~V}$ and PCE also rises from 7.71 to $16.50 \%$. However, with the increase of $n$ value, the films gradually become very coarse with significant deterioration of the fill factor and $V_{\text {oc }}$. Thus, when $n=11$, the photovoltaic performances decrease markedly. Because $\mathrm{NH}_{4} \mathrm{PbI}_{3}$ possesses low relative dielectric constant to $\mathrm{FAPbI}_{3}$ and MAPbI ${ }_{3}$, when increasing $\mathrm{NH}_{4}^{+}$( $n$ decreases) in the A/FA/MA perovskites, the relative dielectric constants decrease which will significantly affect electron transport in a photovoltaic device, with reducing $J_{\mathrm{sc}}$ [37]. Whereas, when $n$ increases, the band gaps of A/FA/MA perovskites reduce, resulting in the absorption and $J_{\text {sc }}$ increase, and the corresponding PCE will change as well with the change of relative dielectric constants and band gaps. Between the effects of the relative dielectric constant and band gaps, there is a suitable $\mathrm{NH}_{4}^{+}$level ( $n$ value) to strike a balance and get an A/FA/MA perovskite device with best photovoltaic performances.

The current-voltage $(J-V)$ curves and photovoltaic parameters of $\left[\left(\mathrm{NH}_{4}\right)_{x}(\mathrm{FA})_{8} \mathrm{~Pb}_{9} \mathrm{I}_{26+x}\right]_{0.85}\left(\mathrm{MAPbBr}_{3}\right)_{0.15}$ $(n=9)$ perovskite based solar cells with different amounts of $\mathrm{NH}_{4} \mathrm{I}(x)$ are depicted in Table $\mathrm{S} 1$. The $J-V$ curves of the devices with A/FA/MA perovskites are plotted in Fig. $4 \mathrm{a}$, and the photovoltaic parameters of the best performance solar devices from the different ratios of FAI and $\mathrm{NH}_{4} \mathrm{I}$ are summarized in Table S2. To obtain highly efficient A/FA/MA ( $n=9)$ PSCs, we optimized the A/FA/ MA perovskite precursor concentrations (1.2, 1.3, 1.4, 1.5 and $1.8 \mathrm{~mol} \mathrm{~L}^{-1}$, based on the total $\mathrm{Pb}^{2+}$ content). Our best A/FA/MA perovskites device was obtained for $n=9$, with a precursor concentration of $1.4 \mathrm{~mol} \mathrm{~L}^{-1}$ in the DMF/DMSO mixed solvent, an annealing temperature of $100^{\circ} \mathrm{C}$ and annealing time of $60 \mathrm{~min}$. The photovoltaic parameters and $J-V$ curves of A/FA/MA $(n=9)$ PSCs with different precursor concentrations are shown in Fig. $4 \mathrm{~b}$ and Table S3. We used this method to maintain the same procedure for the device preparation process to assess accurately the device performance for the different formulations.

We found that PCE of the champion device (Fig. 4c) is $18.25 \%$, and the PCE of normal perovskite-based device is $18.73 \%$. These results are all significantly higher than previous A/FA/MA perovskite based solar cells. The $J-V$ curve characteristics of PSCs are sensitive to measurement speed [39-44]. Here the forward and reverse scans show a negligible hysteresis to A/FA/MA perovskites solar cells. We could demonstrate a highly efficient A/FA/MA PSCs with $V_{\text {oc }}$ of $1.09 \mathrm{~V}, J_{\text {sc }}$ of $22.85 \mathrm{~mA} \mathrm{~cm}^{-2}$, fill factor (FF) of $73.43 \%$, and PCE of $18.25 \%$ for the reverse scan direction and $V_{\mathrm{oc}}$ of $1.09 \mathrm{~V}, J_{\mathrm{sc}}$ of $22.96 \mathrm{~mA} \mathrm{~cm}^{-2}$, FF of $72.77 \%$ and PCE of $18.21 \%$ for the forward scan direction. In this regard, devices have little hysteresis possibly due to the addition of $\mathrm{NH}_{4} \mathrm{I}$ modified to the interface between light-absorber and $\mathrm{TiO}_{2}$ layer, which then induces efficient electron injection and transport.

Fig. $4 \mathrm{~d}$ shows the incident photon to current conversion efficiency (IPCE) spectra for FA/MA $(n=\infty)$ and A/FA/MA $(n=3,5,7,9$ and 11) PSCs. From the IPCE spectra in Fig. 4d, we observe that photocurrent generation starts at about $300 \mathrm{~nm}$. There is an excellent photocurrent response from 300 to $800 \mathrm{~nm}$ shown by the A/FA/MA PSCs. Compared with normal perovskite, they 

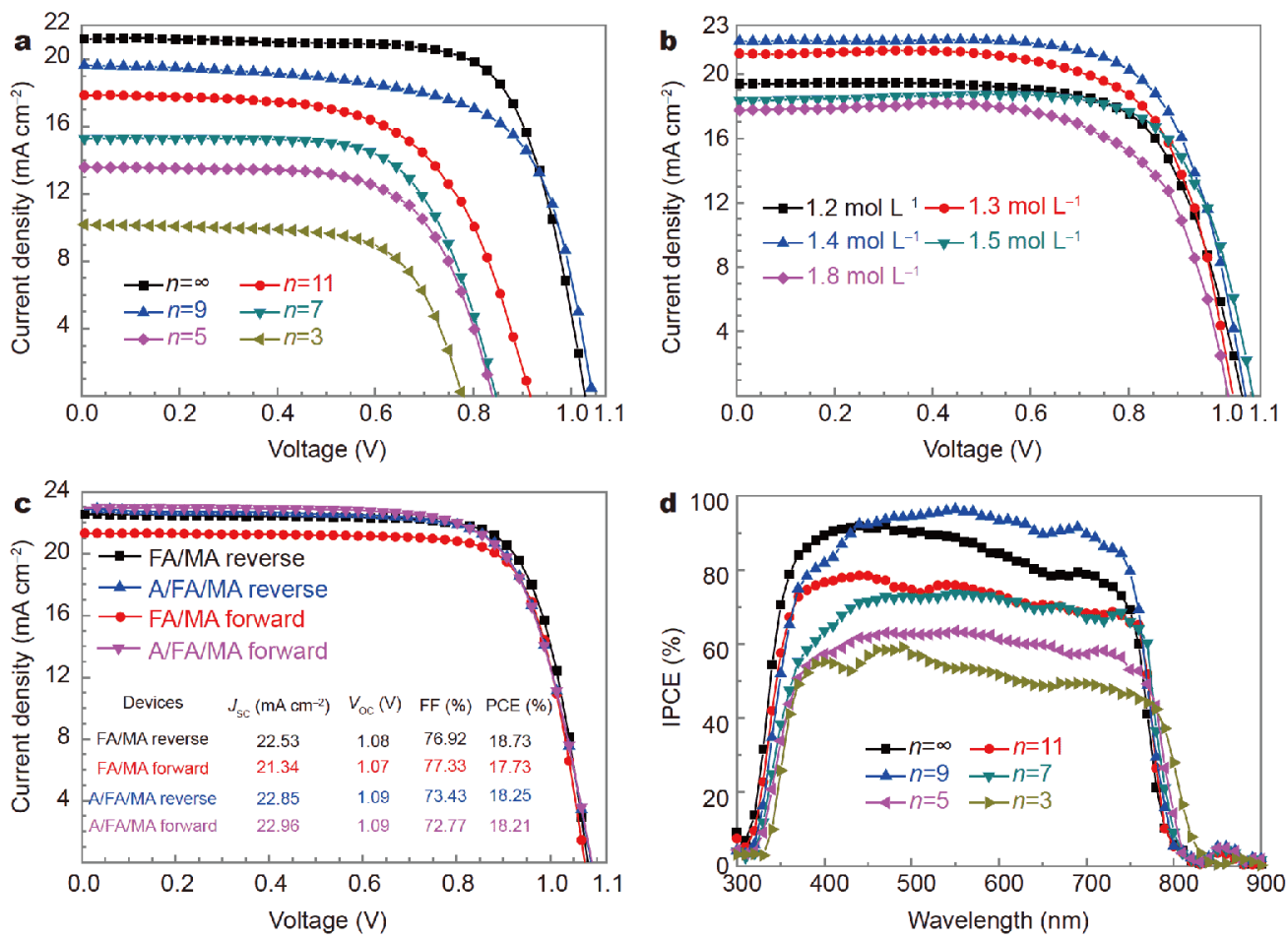

Figure 4 (a) $J-V$ curves of $\left(\mathrm{FAPb}_{3}\right)_{0.85}\left(\mathrm{MAPbBr}_{3}\right)_{0.15}(n=\infty)$ and $\left[\left(\mathrm{NH}_{4}\right)_{2.4}(\mathrm{FA})_{n-1} \mathrm{~Pb}_{n} \mathrm{I}_{3 n+1.4}\right]_{0.85}\left(\mathrm{MAPbBr}_{3}\right)_{0.15}$ perovskites based solar cells with different $n(n=3,5,7,9,11)$. (b) $J-V$ curves of A/FA/MA ( $n=9)$ PSCs with different precursor concentrations. (c) FA/MA perovskite and champion device with A/FA/MA ( $n=9)$ PSCs under reverse and forward scan directions. (d) IPCE spectra of $\left(\mathrm{FAPbI}_{3}\right)_{0.85}\left(\mathrm{MAPbBr}_{3}\right)_{0.15}(n=\infty)$ and $\left[\left(\mathrm{NH}_{4}\right)_{2.4}(\mathrm{FA})_{n-1} \mathrm{~Pb}_{n} \mathrm{I}_{3 n+1.4}\right]_{0.85}\left(\mathrm{MAPbBr}_{3}\right)_{0.15}(n=3,5,7,9$ and 11) PSCs.

show the red-shift of IPCE spectra of A/FA/MA $(n=3,5$, 7,9 and 11) and the IPCE spectrum of A/FA/MA perovskite $(n=3)$ has the most significant red-shift, according to the UV-vis absorption peaks and PL peaks (Fig. 3). When $n=9$, this reaches peak values of over $80 \%$ in the visible spectra, the $J_{\mathrm{sc}}$ is over $22 \mathrm{~mA} \mathrm{~cm}$ and surpass that of normal perovskite, leading to the highest PCE value of A/FA/MA ( $n=9)$ perovskite.

Rapid decomposition of $\mathrm{MAPbI}_{3}$ and $\mathrm{FAPbI}_{3}$ occurs due to illumination and high moisture, which is manifested by a decrease of PCE and the change of the XRD patterns [45]. To investigate the influence of the introduction of ammonium cation on the device stability, we further performed the light and moisture stability tests of FA/MA and A/FA/MA ( $n=9)$ perovskite devices and thin films. Our results show that the A/FA/MA perovskite films exhibit remarkably high reproducibility, enhanced light fastness, and high moisture resistance. In Fig. 5a, we presented normalized efficiency variation curves of the encapsulated FA/MA and A/FA/MA ( $n=9$ ) PSCs under standard AM 1.5G illumination. We observed that the PCE of the encapsulated FA/MA PSCs has a marked decline and almost no efficiency, while the PCE of en- capsulated A/FA/MA ( $n=9)$ perovskite devices is fluctuant, but it shows no evident change and has the tendency to increase after exposure to light.

We performed long-term moisture stability measurements of the FA/MA and A/FA/MA $(n=9)$ perovskite devices and thin films. Normalized efficiency variation and fitting line of unsealed FA/MA and A/FA/MA $(n=9)$ PSCs under the humidity over $90 \%$ over $1,000 \mathrm{~h}$ are shown in Fig. 5b. The PCE of the FA/MA perovskite device markedly degrades, followed by a slow degradation to $<20 \%$ of its original value. In contrast, the A/FA/MA $(n=9)$ perovskite device slowly degrades and retains its original PCE under the humidity over $90 \%$ over $1,000 \mathrm{~h}$. A/FA/MA $(n=9)$ perovskite film almost had no change. The stability of the film was also confirmed by XRD (Fig. $5 \mathrm{c}$ and d). Apparently, in the FA/MA perovskite film, $\mathrm{PbI}_{2}$ peaks are observed, while few $\mathrm{PbI}_{2}$ peaks exist in A/FA/MA $(n=9)$ perovskite film. The $2 \mathrm{D}$ characteristic peaks before $10^{\circ}$ become weak and $3 \mathrm{D}$ characteristic peaks almost have no change. Fig. 5e shows images of six different perovskite films before and after exposure to high humidity. When stored under the humidity over $90 \%$ over $1,000 \mathrm{~h}$, the normal perovskite materials have 

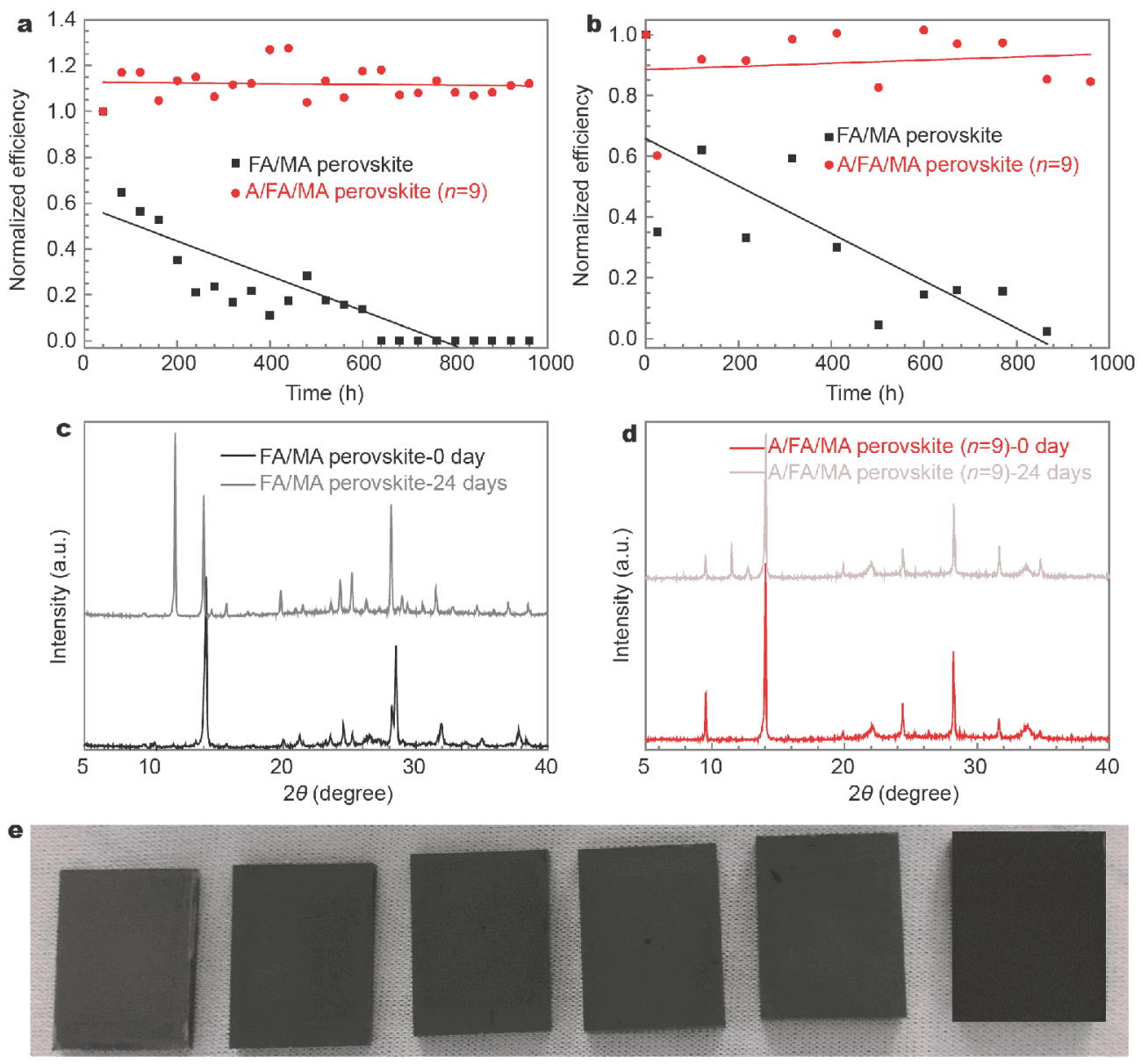
$n=3$
$n=5$
$n=7$
$n=11$
$n=\infty$

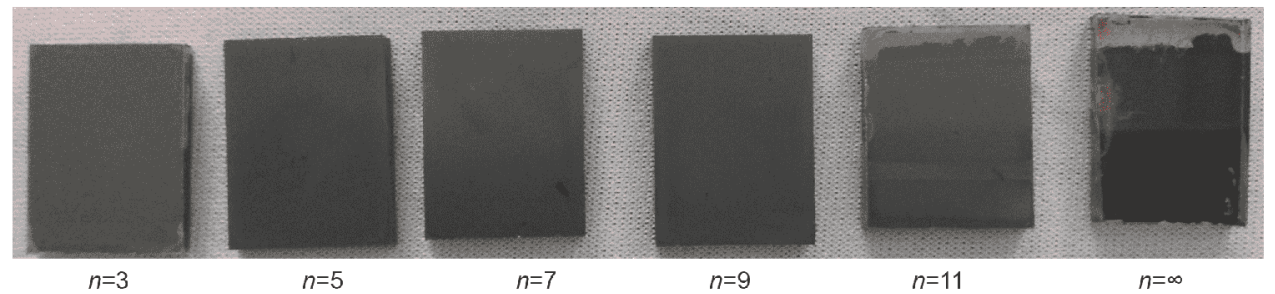

Figure 5 (a) Normalized efficiency variation and fitting line of encapsulated FA/MA and A/FA/MA ( $n=9$ ) PSCs under standard AM 1.5G illumination. (b) Normalized efficiency variation and fitting line of unsealed FA/MA and A/FA/MA ( $n=9$ ) PSCs under RH 90\%. (c), (d) XRD patterns of unsealed FA/MA and A/FA/MA ( $n=9$ ) perovskite films before and after exposing to high humidity. (e) Images of six different perovskite films before and after exposing to high humidity.

remarkable decomposition, while the four kinds of A/FA/MA $(n=9)$ perovskite film have almost no change and then only when $n=11$, the film undergoes partial degradation.

The results indicate that A/FA/MA ( $n=9)$ perovskite has high moisture stability, as the A/FA/MA ( $n=9)$ perovskite systems possess excess $\mathrm{NH}_{4}^{+}$and the cation exchange between $\mathrm{FA}^{+}$and $\mathrm{NH}_{4}{ }^{+}$occurs at the film surface, and thus the $\mathrm{FA}^{+}$and $\mathrm{MA}^{+}$can diffuse inside and the
$\mathrm{NH}_{4}{ }^{+}$ions diffuse to the surface and an insulating "wall" with $2 \mathrm{D}$ layered structure is formed to prevent $3 \mathrm{D}$ perovskite from direct contact with adventitious water [46]. Water molecules will combine with $\mathrm{NH}_{4}{ }^{+}$on the surface, firstly decomposing the $2 \mathrm{D}$ structure and protecting the 3D structure, which decreases the chance of decomposition $[47,48]$. It is consistent with XRD patterns of A/FA/MA ( $n=9)$ perovskite films after exposing to high humidity environment. Moreover, the A/FA/MA ( $n=9)$ 
perovskite device displays the highest PCE and shows the best moisture tolerance.

\section{CONCLUSIONS}

In summary, we have designed and fabricated new-type highly stable A/FA/MA perovskite materials with the final composition of $\quad\left[\left(\mathrm{NH}_{4}\right)_{2.4}(\mathrm{FA})_{n-1} \mathrm{~Pb}_{n} \mathrm{I}_{3 n+1.4}\right]_{0.85^{-}}$ $\left(\mathrm{MAPbBr}_{3}\right)_{0.15}(n=3,5,7,9$ and 11$)$, and then studied their properties. When $n$ is smaller, the light absorption and photoluminescence of these A/FA/MA perovskite films show more shift to the red band region and the $E_{\mathrm{g}}$ decreases. The devices based on these A/FA/MA perovskite materials have good photovoltaic performance; the PCE exceeds $18 \%$ when $n=9$. In addition, these A/FA/MA PSCs have high light stability and excellent moisture resistance, and the PCE is retained when the perovskite layer is exposed to AM $1.5 \mathrm{G}$ standard illumination and high humidity conditions (humidity over $90 \mathrm{RH} \%$ ) over $1,000 \mathrm{~h}$. It indicates that these A/FA/MA perovskite materials have great practical use. The indepth study on these new-type perovskite materials with high efficiency and long-term stability shows promise for a practical application of PSCs.

\section{Received 13 July 2018; accepted 21 August 2018;}

published online 21 September 2018

1 Kojima A, Teshima K, Shirai Y, et al. Organometal halide perovskites as visible-light sensitizers for photovoltaic cells. J Am Chem Soc, 2009, 131: 6050-6051

2 Chen Q, Zhou H, Hong Z, et al. Planar heterojunction perovskite solar cells via vapor-assisted solution process. J Am Chem Soc, 2014, 136: 622-625

3 National Renewable Energy Laboratory (NREL), Best ResearchCell Efficiencies Chart, https://www.nrel.gov/pv/assets/images/efficiency-chart-20180716.jpg, accessed, 2018

4 Yang WS, Noh JH, Jeon NJ, et al. High-performance photovoltaic perovskite layers fabricated through intramolecular exchange. Science, 2015, 348: 1234-1237

5 Wu Y, Wang P, Wang S, et al. Heterojunction engineering for high efficiency cesium formamidinium double-cation lead halide perovskite solar cells. ChemSusChem, 2018, 11: 837-842

6 Lee JW, Seol DJ, Cho AN, et al. High-efficiency perovskite solar cells based on the black polymorph of $\mathrm{HC}\left(\mathrm{NH}_{2}\right)_{2} \mathrm{PbI}_{3}$. Adv Mater, 2014, 26: 4991-4998

7 Juarez-Perez EJ, Hawash Z, Raga SR, et al. Thermal degradation of $\mathrm{CH}_{3} \mathrm{NH}_{3} \mathrm{PbI}_{3}$ perovskite into $\mathrm{NH}_{3}$ and $\mathrm{CH}_{3} \mathrm{I}$ gases observed by coupled thermogravimetry-mass spectrometry analysis. Energy Environ Sci, 2016, 9: 3406-3410

8 Roose B, Baena JPC, Gödel KC, et al. Mesoporous $\mathrm{SnO}_{2}$ electron selective contact enables UV-stable perovskite solar cells. Nano Energy, 2016, 30: 517-522

9 Frost JM, Butler KT, Brivio F, et al. Atomistic origins of highperformance in hybrid halide perovskite solar cells. Nano Lett, 2014, 14: 2584-2590
10 Li CC, Zhang W, Ang H, et al. Compressed hydrogen gas-induced synthesis of $\mathrm{Au}-\mathrm{Pt}$ core-shell nanoparticle chains towards highperformance catalysts for $\mathrm{Li}-\mathrm{O}_{2}$ batteries. J Mater Chem A, 2014, 2: 10676-10681

11 Ito $\mathrm{S}$, Tanaka $\mathrm{S}$, Manabe $\mathrm{K}$, et al. Effects of surface blocking layer of $\mathrm{Sb}_{2} \mathrm{~S}_{3}$ on nanocrystalline $\mathrm{TiO}_{2}$ for $\mathrm{CH}_{3} \mathrm{NH}_{3} \mathrm{PbI}_{3}$ perovskite solar cells. J Phys Chem C, 2014, 118: 16995-17000

12 Leijtens T, Eperon GE, Pathak S, et al. Overcoming ultraviolet light instability of sensitized $\mathrm{TiO}_{2}$ with meso-superstructured organometal tri-halide perovskite solar cells. Nat Commun, 2013, 4: 2885

13 Cheng Z, Lin J. Layered organic-inorganic hybrid perovskites: structure, optical properties, film preparation, patterning and templating engineering. CrystEngComm, 2010, 12: 2646-2662

14 Kaltenbrunner M, Adam G, Głowacki ED, et al. Flexible high power-per-weight perovskite solar cells with chromium oxidemetal contacts for improved stability in air. Nat Mater, 2015, 14: 1032-1039

15 Pan J, Mu C, Li Q, et al. Room-temperature, hydrochloride-assisted, one-step deposition for highly efficient and air-stable perovskite solar cells. Adv Mater, 2016, 28: 8309-8314

16 Bai Y, Dong Q, Shao Y, et al. Enhancing stability and efficiency of perovskite solar cells with crosslinkable silane-functionalized and doped fullerene. Nat Commun, 2016, 7: 12806

17 Saliba M, Matsui T, Seo JY, et al. Cesium-containing triple cation perovskite solar cells: improved stability, reproducibility and high efficiency. Energy Environ Sci, 2016, 9: 1989-1997

18 Peng W, Miao X, Adinolfi V, et al. Engineering of $\mathrm{CH}_{3} \mathrm{NH}_{3} \mathrm{PbI}_{3}$ perovskite crystals by alloying large organic cations for enhanced thermal stability and transport properties. Angew Chem Int Ed, 2016, 55: 10686-10690

19 Bella F, Griffini G, Correa-Baena JP, et al. Improving efficiency and stability of perovskite solar cells with photocurable fluoropolymers. Science, 2016, 354: 203-206

20 Wang Z, Lin Q, Chmiel FP, et al. Efficient ambient-air-stable solar cells with 2D-3D heterostructured butylammonium-caesium-formamidinium lead halide perovskites. Nat Energy, 2017, 2: 17135

21 Smith IC, Hoke ET, Solis-Ibarra D, et al. A layered hybrid perovskite solar-cell absorber with enhanced moisture stability. Angew Chem, 2014, 126: 11414-11417

22 Koh TM, Shanmugam V, Schlipf J, et al. Nanostructuring mixeddimensional perovskites: a route toward tunable, efficient photovoltaics. Adv Mater, 2016, 28: 3653-3661

23 Cao DH, Stoumpos CC, Farha OK, et al. 2D homologous perovskites as light-absorbing materials for solar cell applications. J Am Chem Soc, 2015, 137: 7843-7850

24 Tsai H, Nie W, Blancon JC, et al. High-efficiency two-dimensional Ruddlesden-Popper perovskite solar cells. Nature, 2016, 536: 312316

25 Zhang X, Ren X, Liu B, et al. Stable high efficiency two-dimensional perovskite solar cells via cesium doping. Energy Environ Sci, 2017, 10: 2095-2102

26 Zhang X, Munir R, Xu Z, et al. Phase transition control for high performance Ruddlesden-Popper perovskite solar cells. Adv Mater, 2018, 30: 1707166

27 Ma S, Cai M, Cheng T, et al. Two-dimensional organic-inorganic hybrid perovskite: from material properties to device applications. Sci China Mater, 2018, 61: 1257-1277

28 Car R, Parrinello M. Unified approach for molecular dynamics and density-functional theory. Phys Rev Lett, 1985, 55: 2471-2474

29 Giannozzi P, Baroni S, Bonini N, et al. QUANTUM ESPRESSO: a 
modular and open-source software project for quantum simulations of materials. J Phys-Condens Matter, 2009, 21: 395502

30 Perdew JP, Burke K, Ernzerhof M. Generalized gradient approximation made simple. Phys Rev Lett, 1996, 77: 3865-3868

31 Vanderbilt D. Soft self-consistent pseudopotentials in a generalized eigenvalue formalism. Phys Rev B, 1990, 41: 7892-7895

32 Nosé S. A unified formulation of the constant temperature molecular dynamics methods. J Chem Phys, 1984, 81: 511-519

33 Kieslich G, Sun S, Cheetham AK. Solid-state principles applied to organic-inorganic perovskites: new tricks for an old dog. Chem Sci, 2014, 5: 4712-4715

34 Walsh A. Principles of chemical bonding and band gap engineering in hybrid organic-inorganic halide perovskites. J Phys Chem C, 2015, 119: 5755-5760

35 Fan LQ, Wu JH. $\mathrm{NH}_{4} \mathrm{PbI}_{3}$. Acta Crystlogr E Struct Rep Online, 2007, 63: i189-i189

36 Liu M, Johnston MB, Snaith HJ. Efficient planar heterojunction perovskite solar cells by vapour deposition. Nature, 2013, 501: 395398

37 Brivio F, Walker AB, Walsh A. Structural and electronic properties of hybrid perovskites for high-efficiency thin-film photovoltaics from first-principles. APL Mater, 2013, 1: 042111

38 Brivio F, Butler KT, Walsh A, et al. Relativistic quasiparticle selfconsistent electronic structure of hybrid halide perovskite photovoltaic absorbers. Phys Rev B, 2014, 89: 155204

39 Christians JA, Manser JS, Kamat PV. Best practices in perovskite solar cell efficiency measurements. avoiding the error of making bad cells look good. J Phys Chem Lett, 2015, 6: 852-857

40 Kim HS, Jang IH, Ahn N, et al. Control of $I-V$ hysteresis in $\mathrm{CH}_{3}$ $\mathrm{NH}_{3} \mathrm{PbI}_{3}$ perovskite solar cell. J Phys Chem Lett, 2015, 6: 46334639

41 Chen HW, Sakai N, Ikegami M, et al. Emergence of hysteresis and transient ferroelectric response in organo-lead halide perovskite solar cells. J Phys Chem Lett, 2015, 6: 164-169

42 Kim HS, Mora-Sero I, Gonzalez-Pedro V, et al. Mechanism of carrier accumulation in perovskite thin-absorber solar cells. Nat Commun, 2013, 4: 2242
43 Snaith HJ, Abate A, Ball JM, et al. Anomalous hysteresis in perovskite solar cells. J Phys Chem Lett, 2014, 5: 1511-1515

44 Wei J, Zhao Y, Li H, et al. Hysteresis analysis based on the ferroelectric effect in hybrid perovskite solar cells. J Phys Chem Lett, 2014, 5: 3937-3945

45 Bass KK, McAnally RE, Zhou S, et al. Influence of moisture on the preparation, crystal structure, and photophysical properties of organohalide perovskites. Chem Commun, 2014, 50: 15819-15822

46 Zhou Z, Pang S, Ji F, et al. The fabrication of formamidinium lead iodide perovskite thin films via organic cation exchange. Chem Commun, 2016, 52: 3828-3831

47 Chen $\mathrm{Y}, \mathrm{Li}$ B, Huang W, et al. Efficient and reproducible $\mathrm{CH}_{3}$ $\mathrm{NH}_{3} \mathrm{PbI}_{3-x}(\mathrm{SCN})_{x}$ perovskite based planar solar cells. Chem Commun, 2015, 51: 11997-11999

48 Jiang Q, Rebollar D, Gong J, et al. Pseudohalide-induced moisture tolerance in perovskite $\mathrm{CH}_{3} \mathrm{NH}_{3} \mathrm{~Pb}(\mathrm{SCN})_{2} \mathrm{I}$ thin films. Angew Chem Int Ed, 2015, 54: 7617-7620

Acknowledgements This work was financially supported by the $\mathrm{Na}$ tional Key Research and Development Program of China (2016YFA0202401) and the National Natural Science Foundation of China (51572080). The authors thank Trina Solar which provided the stability measurements and data of unsealed solar-cell devices under the humidity RH $\sim 80 \%$ in SI.

Author contributions Dai S and Pan X conceived the experiments and directed the study. Zheng $\mathrm{H}$ prepared the perovskite films, fabricated the solar-cell devices and wrote this manuscript. Liu G performed the characterization. Zhou K and Zhang B were mainly responsible for the analysis and study of perovskite structure. Alsaedi A and Hayat T carefully reviewed and modified this manuscript. All authors discussed the results and commented on the manuscript.

Conflict of interest The authors declare no conflict of interest.

Supplementary information Supporting data are available in the online version of the paper. 


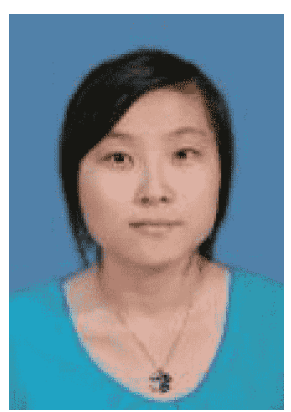

Haiying Zheng received her BSc degree from Hefei University of Technology in 2014. She is currently pursuing her PhD degree in the University of Science and Technology of China. Her current main research is perovskite solar cells.

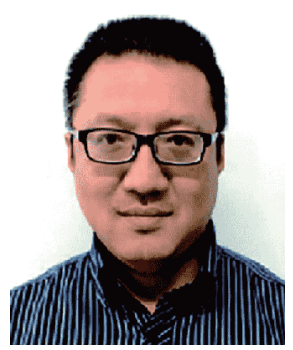

Xu Pan received his PhD degree from the Chinese Academy of Sciences in 2007. He joined Hefei Institutes of Physical Science, Chinese Academy of Sciences and was promoted to full professor in 2013. Now his research interest focuses on the new generation solar cells, including dye-sensitized solar cells and perovskite solar cells, etc.

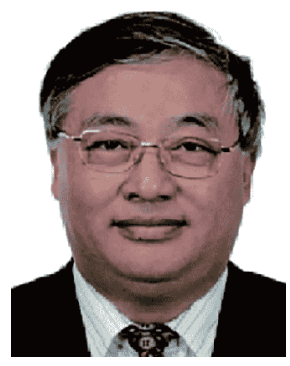

Songyuan Dai is a professor and Dean of the School of Renewable Energy, North China Electric Power University. He obtained his BSc degree in physics from Anhui Normal University in 1987, and MSc and PhD degrees in plasma physics from the Institute of Plasma Physics, Chinese Academy of Sciences in 1991 and 2001. His research interest mainly focuses on next-generation solar cells including dye-sensitized solar cells, quantum dot solar cells, perovskite solar cells, etc.

\section{新型高稳定二维/三维钻针矿材料: 引入铵阳离子对销针矿太阳电池性能的影响}

郑海英 ${ }^{1,2}$, 戴松元 ${ }^{1,3,4^{*}}$, 周凯旋 ${ }^{4}$, 刘国震 ${ }^{1,2}$, 张兵 ${ }^{4}$, Ahmed Alsaedi ${ }^{3}$, Tasawar Hayat ${ }^{3,5}$, 潘旭 ${ }^{1^{*}}$

摘要 钙钛矿太阳电池因其快速增长的效率而引起了广泛关注, 但不稳定性极大的影响了它的实际应用. 这里, 我们首次将小尺寸的 $\mathrm{NH}_{4}{ }^{+}$引入三维钙钛矿中, 制备了新型的二维/三维混合钻钛矿材料. 特别地, 与文献报道的二维钻钛矿不同的是, 新型的二维/三维混合钲 钛矿是首个显示光学性能红移和带隙减少的. 当 $n=9$ 时, 电池显示出优越的光伏性能, 效率达到了 $18.25 \%$, 且具有可忽略的迟滞. 封装的电 池在标准的 AM 1.5G光照下放置1000 小时后, 效率没有明显降低. 在高湿度条件下老化 1000 小时, 未封装的电池保持了 $90 \%$ 的初始效率. 这 些发现为发展新型钙钛矿材料提供了指导, 有助于获得高效稳定的二维钙钛矿太阳电池. 